\title{
Frequency of amoebiasis and other intestinal parasitoses in a settlement in Ilhéus City, State of Bahia, Brazil
}

\author{
Helena Lúcia Carneiro Santos ${ }^{[1]}$, Luci Ana Fernandes Martins ${ }^{[2]}$, \\ Regina Helena Saramago Peralta ${ }^{[3]}$, José Mauro Peralta ${ }^{[4]}$ \\ and Heloisa Werneck de Macedo ${ }^{[3]}$
}

[1]. Laboratório de Avaliação e Promoção da Saúde Ambiental, Instituto Oswaldo Cruz, Fundação Oswaldo Cruz, Rio de Janeiro, RJ. [2]. Programa de Pós Graduação em Patologia, Universidade Federal Fluminense, Rio de Janeiro, RJ. [3]. Departamento de Patologia, Universidade Federal Fluminense, Rio de Janeiro, RJ. [4]. Departamento de Microbiologia, Universidade Federal do Rio de Janeiro, Rio de Janeiro, RJ.

\begin{abstract}
Introduction: This study evaluated the frequency of intestinal parasites, emphasizing the identification and differentiation of Entamoeba spp. Methods: Multiplex polymerase chain reaction (PCR), coproantigen tests and morphometric analysis were performed for Entamoeba spp. differentiation. Results: The overall frequency of intestinal parasites was 65\%. Entamoeba histolytica was detected by the coproantigen test, and the PCR showed that Entamoeba dispar predominated in the population. In contrast, morphometric analysis was important for identifying Entamoeba hartmanni. Conclusions: It is possible to identify the causative agent of amoebiasis and to differentiate this agent from other species by combining techniques.
\end{abstract}

Keywords: Intestinal parasites. Laboratory diagnosis. Amoebiasis.

In tropical countries, intestinal parasites are the leading cause of illness ${ }^{1}$. The frequency of intestinal parasitoses in a population is indicative of that population's socioeconomic development. Such parasitoses are directly associated with educational deficits and poor sanitary conditions, and they constitute a serious public health problem ${ }^{2}$. Amoebiasis is a disease with a worldwide geographic distribution that is most common in tropical regions and developing countries, affects 50 million individuals and causes 110,000 deaths per year. In Brazil, there is a high prevalence of amoebiasis in the northern region ${ }^{3}$. However, the prevalence of Entamoeba histolytica in the country should be reassessed ${ }^{4}$ because the existing epidemiological data are based on the microscopic examination of feces, which does not provide suitably accurate results. In recent years, diagnoses of amoebiasis have focused on the identification of the parasitic antigen in the feces and on the detection of Entamoeba dispar and E. histolytica deoxyribonucleic acid (DNA) by polymerase chain reaction $(\mathrm{PCR})^{5,6}$. Entamoeba hartmanni has smaller dimensions and can thus be differentiated from the E. histolytica/E. dispar complex through the staining and morphometric analysis of cysts and trophozoites.

\footnotetext{
Address to: Dra ${ }^{\mathrm{a}}$ Heloisa Werneck de Macedo. Travessa São Patrício 39, Santa Rosa, 24241-090 Niterói, RJ, Brasil.

Phone: 5521 2629-9108; 5521 9964-3042

e-mail: hwmacedo@terra.com.br

Received 21 December 2012

Accepted 14 August 2013
}

Given these facts, it was important to correctly identify the Entamoeba species present in the studied population. The study was conducted in a settlement located on a cocoa farm located in the municipality of Ilhéus $\left(14^{\circ} 47^{\prime} 6.64^{\prime \prime} \mathrm{S} ; 39^{\circ} 2^{\prime} 16.83^{\prime \prime} \mathrm{W}\right)$ in southern Bahia (BA), which comprised 108 residents distributed across 38 households. The houses had running water, toilets and a closed sewage system. We analyzed fecal samples from 97 residents (males and females aged between 1 and 70 years).

After signing a consent form, the participants answered a questionnaire that gathered relevant information for this study, including age and gender. Approximately $1 \mathrm{~g}$ of each fecal sample was stored in individual flasks containing $5 \%$ buffered formalin solution. The unpreserved fecal sample remainders were fractionated into aliquots and frozen at $-20^{\circ} \mathrm{C}$. The project was approved by the Ethics Committee of the Fluminense Federal University (UFF), Protocol No 020/07.

Stool samples were analyzed using Paratest ${ }^{\mathrm{TM}} / \mathrm{Diagnostek}$ Scientific Products kits (São Paulo, Brazil) and modified Ritchie's methods. Aliquots of each sediment were stained with Lugol's iodine for the observation of parasitic forms. Permanent smears were stained with iron hematoxylin, and the morphometric analysis of cysts was performed using image analysis techniques (Leica Application Suite program, version 3.4.1/Leica Microsystems Ltd. Stereo and Macroscope Systems, Heerbrugg, Switzerland). All samples that tested positive for the E. histolytica/E. dispar complex were stained with iron hematoxylin. Multiplex PCR specific for the detection and differentiation of E. histolytica and E. dispar ${ }^{6}$ and an $E$. histolytica stool antigen test (E. histolytica II enzyme-linked immunosorbent assay) test kit, TECHLAB Inc., Blacksburg, VA, USA) were employed to differentiate the $E$. histolytica/E. dispar 
complex. Statistical analyses of data were performed with the Epi-Info 3.5.1 and Statistical Package for Social Sciences (SPSS) 15 programs. Fisher's test, the chi-square test and McNemar's test were applied at a 5\% significance level.

The overall frequency of intestinal parasitoses was $65 \%$, including 37 (70\%) of 53 analyzed males and $26(59 \%)$ of 44 analyzed females. Table 1 shows that there was no statistically significant difference between sexes $(p=0.27)$. The tested individuals ranged from 1 to 70 years of age, with the highest (81\%) rate of positive cases observed in the 6-to-14 age group, followed by the 15 -to- 55 age group (68\%), the 1-to-5 age group $(50 \%)$ and the above-55 age group (50\%). Table 1 shows that there was no statistically significant difference in incidence among age groups $(\mathrm{p}=0.8)$.

Microscopic examinations indicated that 63 (65\%) samples were positive. Protozoa were found in $92 \%$ of the positive samples, and helminths were found in $51 \%$, whereas 24 (25\%) samples were positive for the E. histolytica/E. dispar complex (Table 1). Monoparasitism was present in 23 (36.5\%) individuals. Among this group, the parasitic species found were Ascaris lumbricoides $(\mathrm{n}=7)$, Entamoeba coli $(\mathrm{n}=6)$, Endolimax nana $(\mathrm{n}=4)$, hookworm $(\mathrm{n}=3)$, the E. histolytica/E. dispar complex $(\mathrm{n}=2)$ and Giardia $(\mathrm{n}=1)$. Co-infection was observed in forty $(63.5 \%)$ individuals: $30.1 \%$ had two parasites, $14.3 \%$ had three parasites, $14.3 \%$ had four parasites, $3.2 \%$ had five parasites, and $1.6 \%$ had six parasites. Of the twenty-four cases positive for the E. histolytica/E. dispar complex, only two cases were monoparasitic. E. histolytica/E. dispar was also present in five cases with two parasites, six cases with three parasites, eight cases with four parasites, two cases with five parasites and one case with six parasites. The frequency of parasites obtained by the modified Ritchie's methods was higher than the values found through the Paratest ${ }^{\mathbb{B}}$ for both the helminth (McNemar's test, $\mathrm{p}<$ 0.001 ) and the protozoa (McNemar's test, $\mathrm{p}<0.05$ ) diagnoses.

The twenty-four samples positive for the E. histolytica/E. dispar complex were evaluated by the coproantigen test and by multiplex PCR. Of these samples, six $(4,5,6,8,14$ and 21) tested positive for $E$. dispar by multiplex PCR, and two (19 and 21) tested positive for E. histolytica by the coproantigen test. Sample 21 showed co-infection, with E. histolytica being identified by the coproantigen test and $E$. dispar by the multiplex PCR method. A morphometric analysis was performed on slides prepared from the twenty-four samples that tested positive for the E. histolytica/E. dispar complex. Cysts with diameters ranging from 3.98 to $6.59 \mu \mathrm{m}$ were found on 10 slides (1, $5,9,11,12,14,18,20,23$ and 24) and were identified as $E$. hartmanni. Slides 6, 13, 16 and 22 showed cysts with diameters above $10 \mu \mathrm{m}$, and $E$. coli cysts were identified on slides 17 and 19. Cysts were not observed on slides 2,10 or 15 , and it was not possible to perform the morphometric analysis on slides $3,4,7,8$ and 21 due to poor preservation. Among the samples that were positive for E. hartmanni, two samples (5 and 14) co-infected with $E$. dispar were observed. The high number of E. hartmanni infections in this study might have been due to a possible retraction of the cysts (Table 2).

Poor health education is an important factor in this population ${ }^{7,8}$.

During this study, we observed that even places with good living conditions, such as access to potable water, sewage systems and paved flooring, had high rates of parasitoses.

TABLE 1 - Distribution of intestinal parasites according to age group and gender.

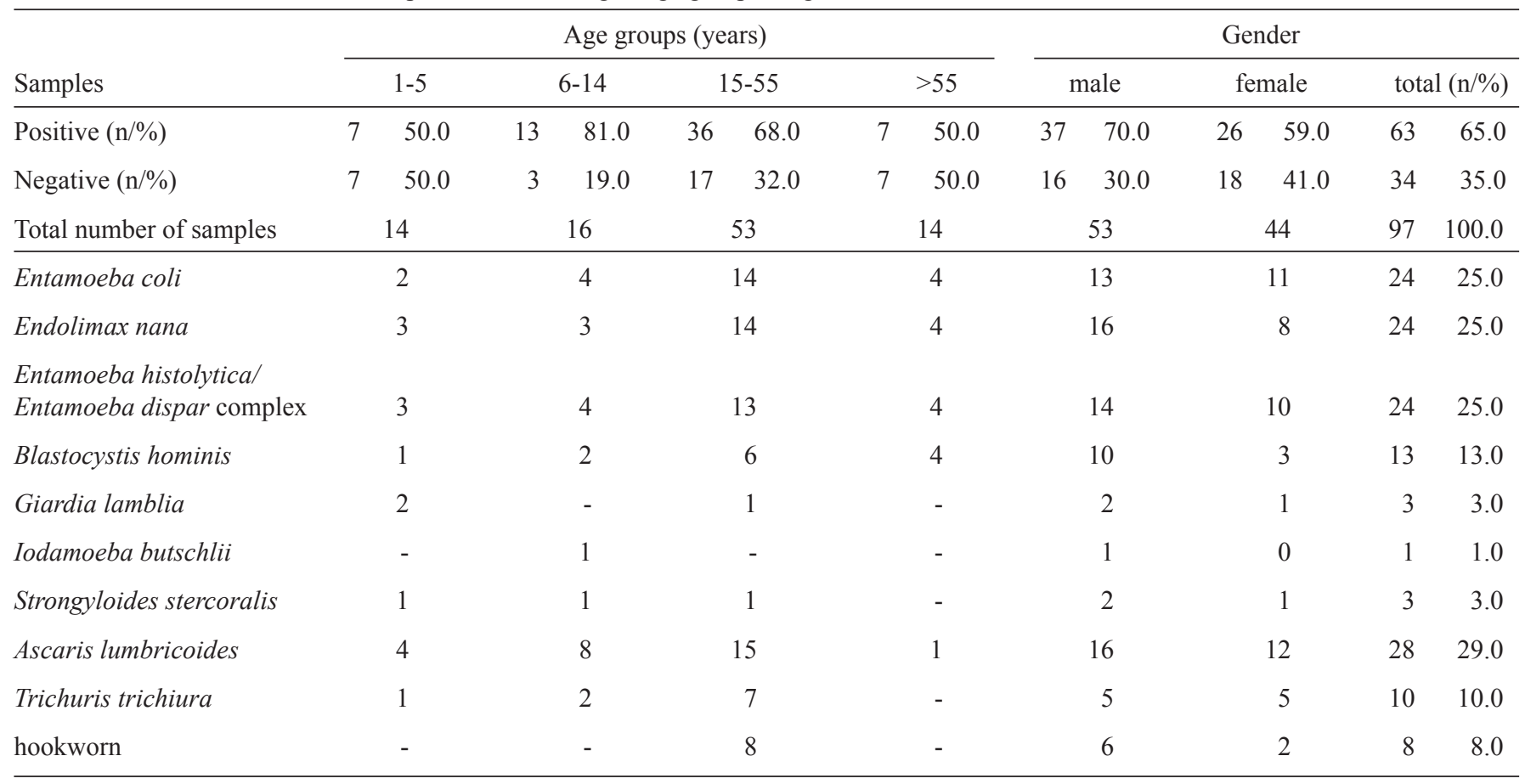


TABLE 2 - Results of morphometric analysis, ELISA and multiplex PCR on the samples that tested positive for the Entamoeba histolytica/ Entamoeba dispar complex using the parasitological stool test.

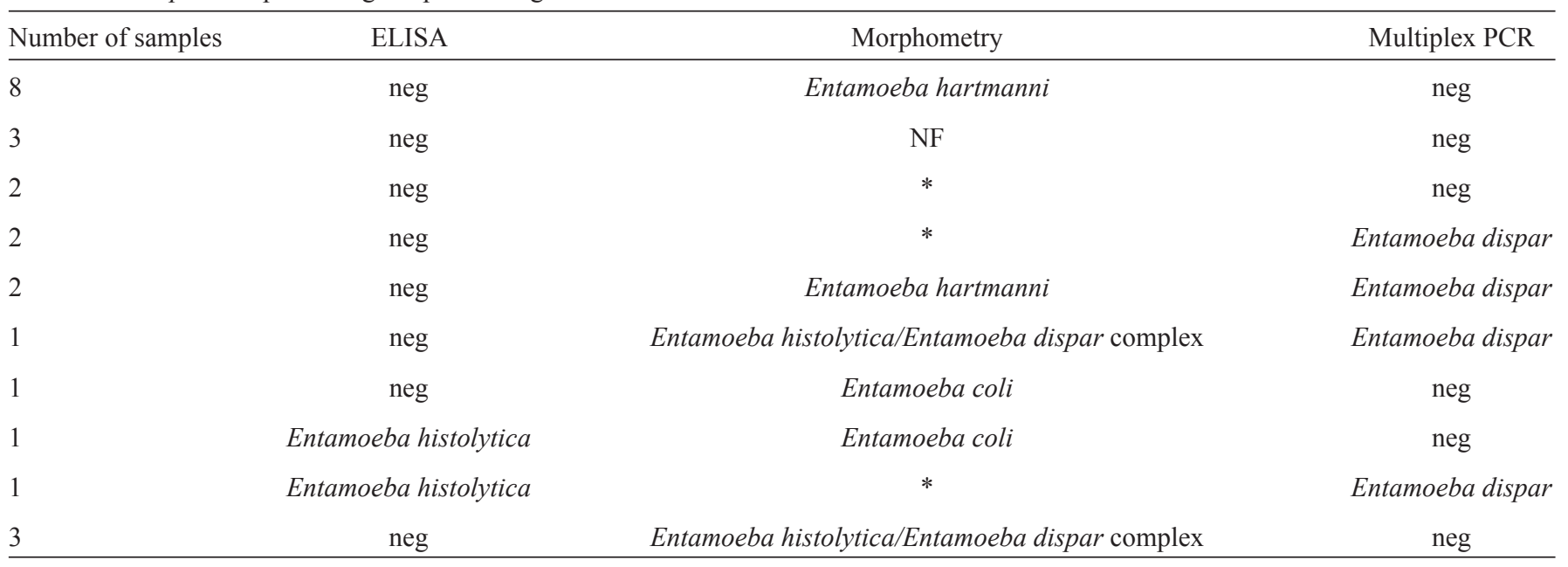

ELISA: enzyme-linked immunosorbent assay; PCR: polymerase chain reaction; neg: negative; NF: not found; *retracted cysts.

The high frequency could be due to ignorance of or resistance to the habits of washing foods that are to be consumed raw and hand washing before meals. Moreover, children are more exposed to parasites due to their greater contact with soil and lack of developed hygiene habits ${ }^{7,9-11}$.

Although the studied population lived on an old cocoa farm in houses with running water, toilets and a closed sewerage system, the area outside of the houses was unpaved. Regardless of this factor, the frequency of intestinal parasites that was found shows that the population was not well informed about the personal hygiene habits required for good health. The uniform distribution of nematode frequency between genders and age groups demonstrated that the entire population was exposed to the external environment in a similar way. This phenomenon may reflect that most of the individuals studied engaged in small farming activities, involving close contact with soil, without using gloves. These individuals work for many hours each day, were likely exposed to improper sanitary conditions and may have failed to perform proper hand hygiene prior to meals. In this study, we found that individuals in homes in which more than one resident was parasitized showed very similar parasitic profiles, again suggesting close contact between people and the dissemination of parasites due to poor personal hygiene or contaminated food, water or hands ${ }^{8}$.

Children tend to be more frequently affected by geohelminths due to their habits of putting their hands in their mouths and walking barefoot. However, in our study, there was no significant difference in the frequency of geohelminth infections between adults and children. Nevertheless, when separately analyzing children up to 14 years $(n=30)$, we found that $20(66.6 \%)$ individuals were parasitized, with a greater number of positive cases in the 6-to-14 age group (65\%) than in the 1-to-5 age group (35\%) (Fisher's test, $\mathrm{p}<0.07)$.

Among the nematodes found, the most common was $A$. lumbricoides (29\%), which was present at a frequency similar to those described for other cities in Northeastern Brazil: $31.2 \%$ in the 7-to-14 age group in Salvador, BA, Brazil ${ }^{10} ; 26 \%$ in a poor community in Feira de Santana, BA ${ }^{12}$; and $33.3 \%$ in a poor community in Fortaleza, State Ceará, Brazil ${ }^{13}$.

High frequencies of the E. histolytica/E. dispar complex (25\%), E. coli (25\%) and E. nana (25\%) were observed among the protozoa found in the community. Few studies have been performed on the occurrence of the E. histolytica/E. dispar complex in BA. However, one study reported a $5 \%$ frequency of the E. histolytica/E. dispar complex ${ }^{14}$ in Salvador, whereas another study observed a $5.5 \%$ frequency of the $E$. histolytica/E. dispar complex, a $20.3 \%$ frequency of $E$. coli and $25.1 \%$ frequency of E. nana.

The results of this study showed a high (63.5\%) frequency of polyparasitism, and we observed a tendency toward a complex association between E. histolytica/E. dispar and $E$. coli and E. nana. Interpersonal contamination could explain the observed high frequency of E. nana (25\%) and E. coli (25\%) in people who maintained close contact (in the same residence or work group). Correct parasitic diagnosis is very important to determine specific treatment and to identify the profile of a given region to establish prevention strategies.

The morphological differentiation of E. histolytica from morphologically similar amoebas based on the immature cysts of E. coli, E. hartmanni and Entamoeba polecki is very difficult. The use of permanent stains minimizes this problem. However, in the case of E. hartmanni, morphometric analysis is also necessary, as this parasite can only be differentiated from the $E$. histolytica/E. dispar complex by cyst diameter ${ }^{11,15}$. Very few studies have reported the use of staining methods or cyst diameter analysis to identify $E$. hartmanni or to differentiate this parasite from the E. histolytica/E. dispar complex. The antigen detection test has high sensitivity and specificity, and according to the diagnostic tests used, E. histolytica can be identified in a sample. However, this method cannot identify other species of 
Entamoeba. Therefore, PCR is more suitable for establishing the epidemiology of $E$. histolytica because this technique allows differentiation between the species within the complex. Few studies in Brazil have truly investigated the prevalence of $E$. histolytica, as these studies did not use methods that permit the differentiation of the E. histolytica/E. dispar complex. Most studies have used microscopy as the only diagnostic method, thus resulting in high percentages for the E. histolytica/E. dispar complex. Several authors have not reported the possible presence of Entamoeba moshkovskii or other amoebas similar to the E. histolytica/E. dispar complex in samples and have stated that all cysts observed by microscopy and not identified as $E$. histolytica were actually E. dispar.

Discrepancies among the enzyme-linked immunosorbent assay (ELISA), microscopy and PCR assay results were observed in sample 19. These discrepancies could be due to false-positive ELISA result or false-negative PCR results. Another possible explanation is that the initial diagnosis was based on a species of amoeba other than E. histolyticalE. dispar. These parasites have several diagnostic morphologic features that may overlap, depending on the conditions of the specimen. Furthermore, the distribution of peripheral chromatin and the position of the karyosome in cysts may not be clearly visible. This diagnosis can thus be one of the most difficult to achieve.

An important factor to consider is that, of the twenty-four samples that tested positive for the E. histolytica/E. dispar complex by microscopy, only two (8.3\%) tested positive for $E$. histolytica by ELISA, and none tested positive by PCR. These findings reinforce the need to identify Entamoeba species prior to selecting a treatment.

This study essentially emphasized the benefits of multiplex PCR, the E. histolytica stool antigen test and morphometric analyses, and we recommend the use of these tools in the routine diagnosis of amoebiasis and in epidemiological studies of Entamoeba spp. in Brazil. The presence of intestinal parasites in the population indicates the need for a more comprehensive epidemiological study in the region, as well as the establishment of public policies to educate the public about the prevention of intestinal parasites.

\section{CONFLICT OF INTEREST}

The authors declare that there is no conflict of interest.

\section{REFERENCES}

1. World Health Organization. Working to overcome the global impact of neglected tropical diseases. First WHO report on neglected tropical diseases; 2010.

2. Agudelo-Lopez S, Gomez-Rodriguez L, Coronado X, Orozco A, ValenciaGutierrez CA, Restrepo-Betancur LF, et al. Prevalencia de parasitosis Intestinales y factores asociados en un corregimiento de la costa atlántica colombiana. Rev Salud Publica 2008; 10:633-642.

3. Silva MCM, Monteiro CSP, Araújo BAV, Silva JV, Póvoa MM. Determinação da infecção por Entamoeba histolytica em residentes da área metropolitana de Belém, Pará, Brasil, utilizando ensaio imunoenzimático (ELISA) para detecção de antígenos. Cad Saude Publica 2005; 21:969-973.

4. Povoa MM, Arruda JE, Silva MC, Bichara CN, Esteves P, Gabbay YB, et al. Diagnóstico de amebíase intestinal utilizando métodos coproscópicos e imunológicos em amostra da população da área metropolitana de Belém, Pará, Brasil. Cad Saude Publica 2000; 16:843-846.

5. Moon JH, Cho SH, Yu JR, Lee WJ, Cheun HI. PCR Diagnosis of Entamoeba histolytica cysts in stool samples. Korean J Parasitol 2011; 49:281-284

6. Santos HL, Peralta RH, Macedo HW, Barreto MG, Peralta JM. Comparison of PCR-Multiplex and antigen detection for differential diagnosis of Entamoeba histolytica. The Braz J Infect Dis 2007; 11:365-370.

7. Moraes Neto AH, Pereira AP, Alencar MF, Souza Jr PR, Dias RC, Fonseca JG, et al. Prevalence of intestinal parasites versus knowledge, attitudes, and practices of inhabitants of low-income communities of Campos dos Goytacazes, Rio de Janeiro State, Brazil. Parasitol Res 2010; 107:295-307.

8. Ferreira GR, Andrade CF. Alguns aspectos socioeconômicos relacionados a parasitoses intestinais e avaliação de uma intervenção educativa em escolares de Estiva Gerbi, SP. Rev Soc Bras Med Trop 2005; 38:402-405.

9. Machado ER, Santos DS, Costa-Cruz JM. Enteroparasites and commensals among children in four peripheral districts of Uberlândia, State of Minas Gerais. Rev Soc Bras Med Trop 2008; 41:581-585.

10. Prado MS, Barreto ML, Strina A, Faria JAS, Nobre AA, Jesus SR, et al. Prevalência e intensidade da infecção por parasitas intestinais em crianças na idade escolar na Cidade de Salvador (Bahia, Brasil). Rev Soc Bras Med Trop 2001; 34:99-101

11. Rey L. Parasitologia. $4^{\text {rd }}$ ed. Rio de Janeiro: Guanabara Koogan; 2008.

12. Santos JF, Correa JE, Gomes SSBS, Silva PC, Borges SA. Estudo das parasitoses intestinais na comunidade carente dos bairros periféricos do município de Feira de Santana (BA), 1993-1997. Sitientibus 1999; 20:55-67.

13. Braga LL, Mendonça Y, Paiva CA, Sales A, Cavalcante AL, Mann BJ, et al. Seropositivity for and Intestinal Colonization with Entamoeba histolytica and Entamoeba dispar in Individuals in Northeastern Brazil. J Clin Microbiol 1998; 36:3044-3045.

14. Santos LP, Santos FLN, Soares NM. Prevalência de parasitoses intestinais em pacientes atendidos no hospital universitário Professor Edgar Santos, Salvador - Bahia. Rev Patol Trop 2007; 36:237-246.

15. Garcia LS. Intestinal protozoa: amebae. In: Garcia LS, editor. Diagnostic medical parasitology, $5^{\text {th }}$ Washington: ASM Press; 2007. p. 6-25. 